\title{
The NLRP3 inflammasome in traumatic brain injury: potential as a biomarker and therapeutic target
}

\author{
William T. O'Brien', Louise Pham², Georgia F. Symons ${ }^{1}$, Mastura Monif ${ }^{1,3,4,5}$, Sandy R. Shultz ${ }^{1,6}$ and \\ Stuart J. McDonald ${ }^{1,2^{*}}$
}

\begin{abstract}
There is a great clinical need to identify the underlying mechanisms, as well as related biomarkers, and treatment targets, for traumatic brain injury (TBI). Neuroinflammation is a central pathophysiological feature of TBI. NLRP3 inflammasome activity is a necessary component of the innate immune response to tissue damage, and dysregulated inflammasome activity has been implicated in a number of neurological conditions. This paper introduces the NLRP3 inflammasome and its implication in the pathogenesis of neuroinflammatory-related conditions, with a particular focus on TBI. Although its role in TBI has only recently been identified, findings suggest that priming and activation of the NLRP3 inflammasome are upregulated following TBI. Moreover, recent studies utilizing specific NLRP3 inhibitors have provided further evidence that this inflammasome is a major driver of neuroinflammation and neurobehavioral disturbances following TBI. In addition, there is emerging evidence that circulating inflammasome-associated proteins may have utility as diagnostic biomarkers of neuroinflammatory conditions, including TBI. Finally, novel and promising areas of research will be highlighted, including the potential involvement of the NLRP3 inflammasome in mild TBI, how factors such as biological sex may affect NLRP3 activity in TBI, and the use of emerging biomarker platforms. Taken together, this review highlights the exciting potential of the NLRP3 inflammasome as a target for treatments and biomarkers that may ultimately be used to improve TBI management.
\end{abstract}

Keywords: Neuroinflammation, TBI, Concussion, Mild traumatic brain injury, Chronic traumatic encephalopathy, Microglia, IL-1ß, Cytokine, Caspase-1, IL-18

\section{Background}

Traumatic brain injury (TBI) is a subset of acquired brain injury which is induced by an external mechanical force sustained to the head or neck [1]. Although commonly described as a silent epidemic, TBI is reported to be one of the leading causes of long-term disability and equates to a global annual economic burden of an estimated $\$ 400$

\footnotetext{
* Correspondence: stuart.mcdonald@monash.edu

'Department of Neuroscience, Monash University, Melbourne, VIC, Australia ${ }^{2}$ Department of Physiology, Anatomy and Microbiology, La Trobe University, Bundoora, VIC 3086, Australia

Full list of author information is available at the end of the article
}

billion [2]. TBI is a highly heterogeneous injury that can cause a range of temporary or permanent neurological alterations [3] and is often categorized into three injury severities: mild, moderate, and severe. These classifications are most commonly defined utilizing the Glasgow coma scale [4]. While TBIs on the mild spectrum were traditionally considered an innocuous injury, recently there has been developing awareness of the potential long-term implications of mild TBI (mTBI), and particularly in relation to repeated mTBIs. The most well publicized long-term implication of repeated mTBIs is the potential development of chronic neuroinflammatory-related conditions such as 
chronic traumatic encephalopathy (CTE), Alzheimer's disease, Parkinson's disease, depression, and anxiety [5-9].

Despite extensive basic and clinical science research on TBI to date, no therapeutic interventions have been successfully implemented to improve patient outcomes [10]. A key factor that has contributed to previous translational failures in TBI is the lack of a detailed understanding of the complex underlying cellular and molecular sequelae. TBI is considered a "biphasic injury" characterized by an initial primary injury and a delayed secondary injury [11]. Primary injury refers to the immediate damage which is caused directly by the mechanical injury, whereas secondary injury refers to further damage due to the pathophysiological changes induced by the primary injury [12]. As secondary injuries can be initiated minutes to hours following injury, and can persist for months to years [13], a greater understanding of the mechanisms of secondary injury may facilitate the discovery of treatments that can improve TBI outcomes. Moreover, a greater understanding of the underlying pathophysiology may facilitate the discovery of diagnostic and prognostic biomarkers of TBI.

Among the different mechanisms postulated to contribute to secondary injury, a neuroinflammatory response characterized by the release of pro-inflammatory mediators and activation of microglia and astrocytes may be universal across TBI subtypes [14-17]. This review will focus on the neuroinflammatory response following TBI, with particular attention to the potentially central role played by a complex of proteins known as the nucleotide-binding oligomerization domain-like receptor pyrin domaincontaining-3 (NLRP3) inflammasome.

\section{Neuroinflammation and TBI}

Neuroinflammation is a key cellular and molecular feature of the central nervous system (CNS) response to insults such as a trauma [18]. Microglia, the resident innate immune cells of the CNS, are known to be mediators of the neuroinflammatory response that occurs following TBI $[15,16,19]$. The activation of these cells induces a multitude of inflammatory cascades, including the production and release of downstream pro-inflammatory cytokines such as interleukin (IL)-1 $\beta$ [20]. As such, microglia play a critical role in the CNS immune defense [21]. While neuroinflammation has a crucial neuroprotective role, a dysregulated or persistent neuroinflammatory response may contribute to neurological symptoms and neurodegeneration [22]. For example, it is postulated that dysregulated neuroinflammation likely plays a key role in the aftermath of even mTBIs, and may underlie the persistent post-concussive symptoms that occur in $10-15 \%$ of mTBI cases [23]. In addition, with increasing evidence that chronic neuroinflammation can trigger various neuropathological changes including hyperphosphorylation of tau and neuronal apoptosis [24, 25], neuroinflammation may be a key mechanism underlying the increased risk for neurodegenerative diseases for those with a history of TBI $[14,26]$.

One family of important regulators of the innate immune system is the NOD-like receptors (NLRs) [27]. NLRs are a family of cytosolic pattern recognition receptors typically formed by three components: a sensor molecule, an adaptor protein, and an effector component. Following activation, these subunits combine to form a pro-inflammatory, multiprotein complex termed an inflammasome [28]. Among the multiple NLRs expressed in mammals, the NLRP3 has been the most extensively studied.

\section{The NLRP3 inflammasome}

The NLRP3 inflammasome is a multiprotein complex, composed of three protein subunits: a sensor molecule, NLRP3, an adaptor protein, ASC, and an effector protein, caspase-1 (Fig. 1) [29]. The functional regulation of an active NLRP3 inflammasome is a two-step process; a nonactivating "priming" stimulus is firstly required to initiate expression of key inflammasome components, followed by a secondary "activating" stimulus that results in inflammasome oligomerization [30,31]. Inflammasome priming includes the transcriptional upregulation of NLRP3 and pro-IL-1 $\beta$, as well as post-translational modifications of NLRP3 that stabilize the inactive protein in a signalcomponent state. These molecules are inactive until a subsequent (or prolonged) stimulus occurs. The subsequent activation induces the assembly of NLRP3 constituent proteins into the complete NLRP3 inflammasome. This process involves the oligomerization of NLRP3 proteins via homotypic interactions between two NLRP3 proteins, which then recruit and bind ASC. The ASC domain of the partially assembled inflammasome then cleaves procaspase-1 into its active isomer, caspase- 1 , and subsequently binds caspase- 1 to form a complete NLRP3 inflammasome. Seven NLRP3 inflammasome molecules are recruited and bind together to form a ring structure. This structure allows the self-cleavage and further activation of pro-caspase- 1 proteins into caspase-1. Caspase-1 then facilitates IL-1 $\beta$ and IL-18 maturation via the cleavage of their inactive pro-isomers (pro-IL-1 $\beta$ and pro-IL$18)$ into their active formation $[28,32]$. These cytokines are involved in the innate immune response to infection and trauma, creating a generalized pro-inflammatory environment [33]. As such caspase-1, IL-1 $\beta$, and IL-18 are commonly utilized in research as indicators of NLRP3 activation. While some NLRP3 inflammasome activity is a necessary component of the innate immune response to pathogens and tissue damage [34], excessive NLRP3 inflammasome activity can lead to a form of cell necrosis known as pyroptosis [35]. 


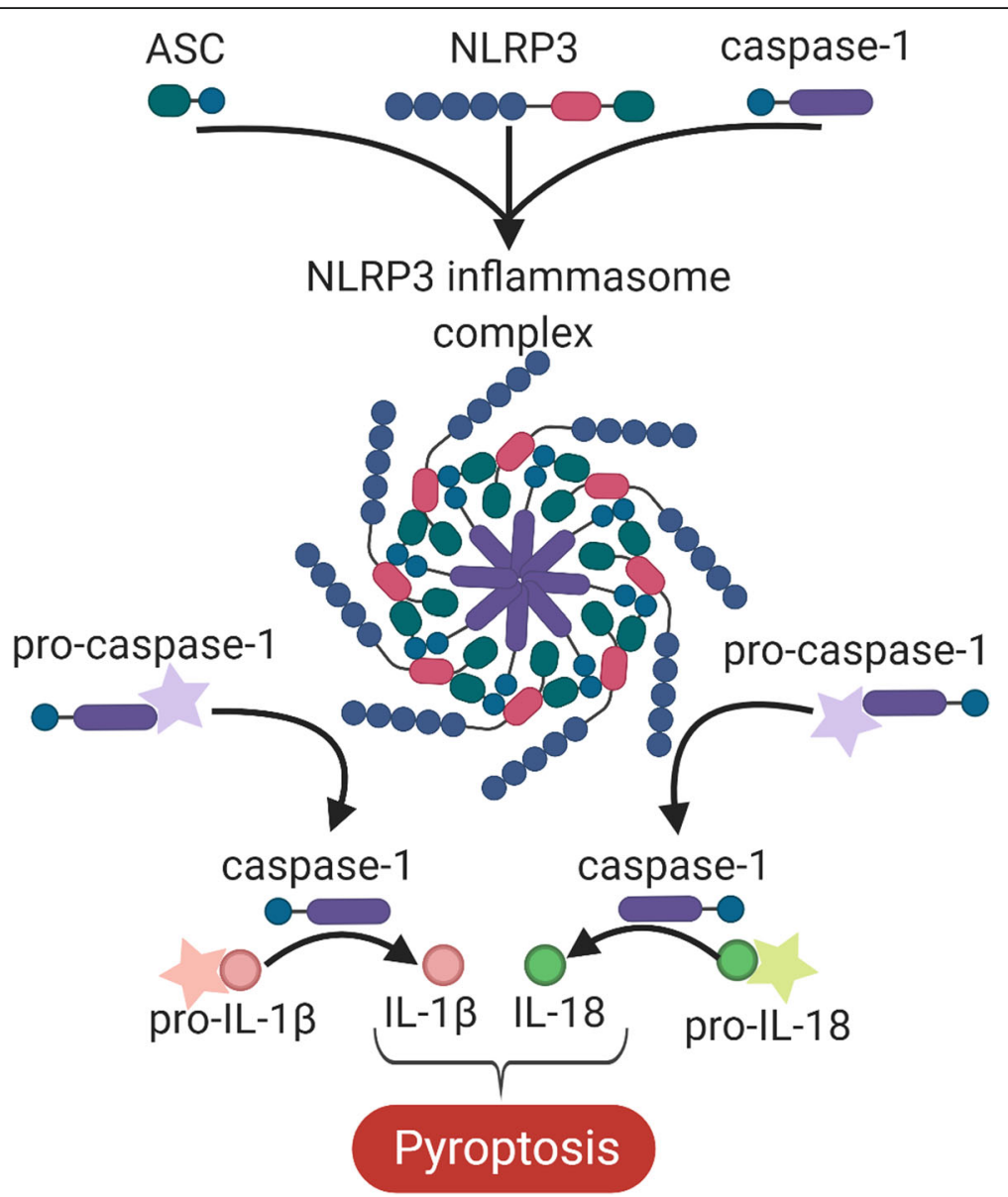

Fig. 1 Formation of the NLRP3 inflammasome. Activation of the NLRP3 inflammasome involves the constituent molecules of the NLRP3 inflammasome (i.e. NLRP3, ASC and caspase-1) binding to form a complete NLRP3 inflammasome complex. This inflammasome complex allows the cleavage of pro-caspase-1 into its active isomer, caspase-1, which in turn cleaves pro-IL-1 $\beta$ and pro-IL-18 to their active isomers IL-1 $\beta$ and IL18 respectively. The increase in these pro-inflammatory proteins ultimately leads to pyroptosis

Multiple signals are known to activate the NLRP3 inflammasome. The signals most commonly investigated are damage-associated molecular pattern (DAMP) and the pathogen-associated molecular pattern molecules [36]. In response to trauma, DAMPs such as reactive oxygen species (ROS) [37], high mobility group box 1 (HMGB1) [38], extracellular matrix molecules [39], and heat shock proteins [40] are known to promote priming of the NLRP3 inflammasome through toll-like receptor (TLR) and NF- $\mathrm{KB}$ signaling [30]. In addition, trauma can produce a range of activating signals, including but not limited to the following: ionic changes such as potassium and chloride efflux, sodium and calcium efflux, altered calcium signaling [41-44]; the presence of extracellular ATP [45]; lysosomal destabilization [46]; and products of mitochondrial dysfunction such as mitochondrial DNA and ROS $[47,48]$. The precise stimuli that promote the priming and activation steps are not yet fully understood, and there is now evidence that some stimuli, such as ROS, may be involved in both processes [37, 49, 50]. For detailed reviews on the priming and activation of the NLRP3 inflammasome, the reader is referred to articles by Swanson et al. [31], Patel et al. [49], and Herman et al. [51]. Importantly, the aforementioned priming and activating stimuli have been implicated in the aftermath of TBI (see [52-54] reviews), and as such, may play a key role in generating a significant neuroinflammatory response (see Fig. 2).

The potential contribution of the NLRP3 inflammasome to disease pathogenesis was first investigated after a gain-of-function mutation in the NLRP3 coding gene was described as a possible cause of the inflammatory condition cryopyrin-associated periodic syndrome [55]. Since this first report, there has been vast interest in determining the relationship between NLRP3 activation and other inflammatory conditions including type 2 diabetes, atherosclerosis, and steatohepatitis, among others [56-58]. Furthermore, while the expression of NLRP3 in 


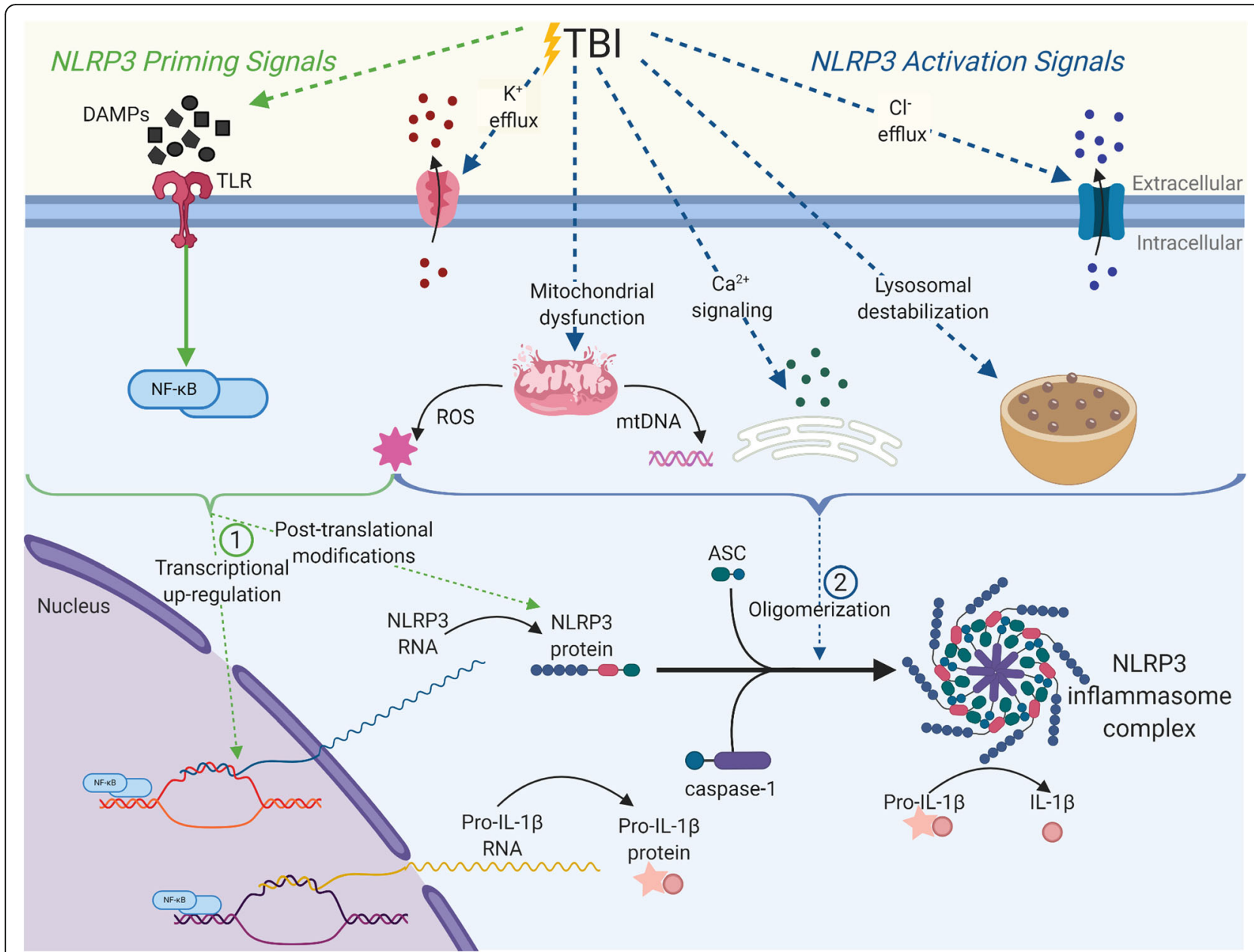

Fig. 2 Potential NLRP3 inflammasome priming and activation 1 following TBI. TBI is known to induce an array of molecular changes that may trigger the two-step activation of the NLRP3 inflammasome. (1) Priming of the inflammasome induces transcriptional up-regulation of NLRP3 and pro-IL-1 $\beta$ as well as post-translational modifications of the NLRP3 protein. The most commonly investigated priming signals in the context of sterile trauma is the recognition of DAMPs to induce TLR-NF-KB signalling. DAMPs such as ROS, HMGB1, extracellular matrix molecules and heat shock proteins are known to prime the NLRP3 inflammasome and have also been shown to be up-regulated following TBI. (2) Activation of the inflammasome occurs following priming, and involves the formation of the NLRP3 inflammasome from its constituent proteins (NLRP3, ASC and caspase-1). TBI features a range of endogenous changes that can serve as activating signals, including but not limited to: ionic changes such as potassium and chloride efflux, sodium and calcium efflux, altered calcium signalling, lysosomal destabilisation and products of mitochondrial dysfunction such as mitochondrial DNA and ROS. Importantly, some signals have been shown to upregulate both priming and activation of the NLRP3 inflammasome. This complete inflammasome complex ultimately results in the release of IL-1 $\beta$.

neurons has been disputed, its expression has consistently been found in microglia and astrocytes [59-61]. As such, NLRP3 activity is receiving growing interest as a contributor to various CNS conditions in which gliamediated neuroinflammation has been associated with disease progression such as Alzheimer's disease, stroke, Parkinson's disease, amyotrophic lateral sclerosis, multiple sclerosis, and pneumococcal meningitis [62-68]. Although the NLRP3 inflammasome was not investigated in the context of TBI until 2013, there is now mounting evidence implicating this inflammasome as a critical component in the pathogenesis of the secondary damage that occurs following TBI.

\section{The NLRP3 inflammasome and TBI Moderate and severe TBI}

The first study to investigate the NLRP3 inflammasome in TBI was performed by Liu et al., with the authors finding an upregulation of NLRP3-related genes and proteins in the cortex of rats within the first week following a moderate TBI (modified weight drop model) [61]. Specifically, they reported an elevation of markers of both inflammasome priming (i.e., NLRP3, ASC, and pro-caspase- $1 \mathrm{mRNA}$ and protein) and activation (i.e., caspase-1, IL-1 $\beta$, and IL-18 protein). Most of these inflammasome markers were upregulated at $6 \mathrm{~h}$ following injury, and remained elevated until the experimental 
end point at 7 days post-injury [61]. Since this initial publication, there has been a surge of studies investigating the NLRP3 inflammasome in the context of preclinical TBI. These studies have supported the research performed by Liu et al., consistently showing an upregulation of the NLRP3 inflammasome, at both a gene and protein level following a moderate TBI induced via controlled cortical impact (CCI) [69, 70].

There has been limited research investigating the NLRP3 inflammasome in the context of human TBI. One study performed by Lin et al. found an upregulation of NLRP3, caspase- 1 , IL-1 $\beta$, and IL-18 protein in the surgically resected cortex of severe-TBI patients in comparison with that of epilepsy patients [71]. Another recent clinical study analyzed cerebrospinal fluid (CSF) from severe-TBI pediatric patients at four time points post-injury, ranging from $<24 \mathrm{~h}$ to $>72 \mathrm{~h}$ [72], finding that pediatric TBI patients had higher CSF levels of NLRP3 than their age-matched controls (i.e., patients without TBI who underwent a lumbar puncture to rule out CNS infection). Furthermore, a CSF NLRP3 concentration $>6.63 \mathrm{ng} / \mathrm{ml}$ at any time point was associated with poorer neurological outcome as determined by the Glasgow Outcome Scale at 6 months post-TBI. This study provided the first evidence of the potential utility of NLRP3 as a fluid-based prognostic biomarker of TBI outcomes. Taken together, these studies have provided clinical evidence of NLRP3 inflammasome activity in moderate and severe TBI.

\section{Mild TBI}

There is likely to be considerable overlap with certain aspects of mild, moderate and severe TBI pathophysiology. Evidence is mounting suggesting that neuroinflammation plays an influential role in the aftermath of mTBI, with a number of recent pre-clinical studies showing that microglial and astrocytic activation can also be prominent in this form of injury [73-76]. There is limited clinical research on glial activation following mTBI; however, the emergence of positron emission tomography (PET) tracers that bind to the $18 \mathrm{kDa}$ translocator protein (TSPO) that is associated with microglia has enabled in vivo clinical imaging of microglial activation. Eber et al. found that at 1-2 weeks and 3-4 months postmTBI, patients who had sustained an mTBI had significantly higher TSPO binding when compared to healthy controls [77]. Additionally, a preliminary study of former athletes with an extensive history of mTBI found significantly higher TSPO expression in comparison to healthy age-matched controls [78]. Combined, these preliminary studies suggest that microglial activation may be a prominent feature of single and repeated mTBI.

Despite evidence indicating that neuroinflammation and specifically, glial activation, contribute to the pathogenesis of TBI, to the best of our knowledge, no studies have directly investigated the role of the NLRP3 inflammasome in mTBI. Studies have instead investigated IL-1 $\beta$, a protein induced by multiple mechanisms, including activation of NLRP3 inflammasome [31, 79]. One study found that rodents administered a single mTBI had an increase in cortical IL- $1 \beta$ protein levels at $6 \mathrm{~h}$ post-impact [80]. Interestingly, no difference was found at $3 \mathrm{~h}$ following injury indicating a potential delay in the inflammatory response to mTBI [80]. Furthermore, the influence of repeat mTBI on IL-1 $\beta$ levels has also been investigated. Mice given two mTBIs (via modified weight drop) separated by 3 days had an upregulation of IL-1 $\beta$ mRNA in the forebrain 3 days following the final injury [81]. This upregulation was only temporary, with mRNA levels not significantly different to sham-injured controls when the animals were allowed to recover for 20 days [81]. Similarly, mice given two mTBIs separated by $24 \mathrm{~h}$ also had elevated cortical IL- $1 \beta$ protein levels that peaked at $48 \mathrm{~h}$ following the final injury and were no different to shams at 7 and 14 days [82].

There is now evidence that neuroinflammation, and specifically glial activation, and IL- $1 \beta$ are prominent in the aftermath of both single and repeated mTBI [78, 80-82]. Nonetheless, while the NLRP3 inflammasome causes the cleavage of IL-1 $\beta$ from its inactive isomer, IL-1 $\beta$ is not specific to the NLRP3 inflammasome. As such, increases in IL-1 $\beta$ may not necessarily indicate NLRP3 inflammasome activity, with future studies required to determine functionality of this inflammasome following mTBI.

\section{NLRP3 as a therapeutic target for TBI}

The aforementioned evidence that TBI can activate the NLRP3 inflammasome has led to the hypothesis that therapies targeting this pathway may be effective for mitigating neuroinflammation and improving TBI recovery. In animal models of other neuroinflammatoryrelated conditions such as Alzheimer's disease and stroke, knock-down or knock-out of NLRP3 has been shown to decrease neuroinflammation as well as improve functional outcomes [62, 63]. In addition, a number of recent studies have found that pharmacological treatments that directly or indirectly target this inflammasome can reduce its activity following moderate-to-severe TBI. These treatments are broadly broken into four groups: (i) treatments derived from naturally occurring compounds (e.g., mangiferin [83], omega-3 fatty acids [71], and apocynin [84]); (ii) repurposed medications (e.g., propofol [85], and telmisartan [86]); (iii) inhibitors of NLRP3-associated molecules (e.g., ASC antibodies [87], NF-kB inhibitor, Bay 117082 [88-91]); and (iv) specific NLRP3 inflammasome inhibitors (e.g., MCC950 [69], JC-124 [92]). While the first three treatment categories have been shown to decrease 
Table 1 Specific and non-specific NLRP3 inhibitors investigated in the context of TBI

\begin{tabular}{lllll}
\hline Inhibitor & NLRP3 specific? & $\begin{array}{l}\text { Pre-clinical } \\
\text { TBl studies }\end{array}$ & Species & Model of TBI \\
\hline MCC950 & $\begin{array}{l}\text { Yes (NLRP3 } \\
\text { NACHT domain) }\end{array}$ & {$[70][69][93]$} & Mouse & CCl \\
JC124 & Yes (unknown) & {$[92]$} & Rat & CCl \\
Bay 11-7082 & No & {$[88-91]$} & $\begin{array}{l}\text { Rat and } \\
\text { Cl, weight- } \\
\text { drop, and fluid }\end{array}$ \\
Mangiferin & No & & mouse & percussion \\
Omega-3 & No & {$[83]$} & Rat & Blast \\
fatty acids & & {$[71]$} & Rat & CCl \\
Apocynin & No & {$[84]$} & Mouse & CCl \\
Propofol & No & {$[85]$} & Rat & Blast \\
Telmisartan & No & {$[86]$} & Mouse & Cryogenic \\
\hline
\end{tabular}

NLRP3 inflammasome activity as well as demonstrating a neuroprotective effect, they do not target NLRP3 activation specifically. As such, it is difficult to determine whether the improved outcomes are NLRP3 inflammasome dependent, or whether the NLRP3 inflammasome changes are the result of an alternative mechanism of action (e.g., reduction in activating stimuli). Hence, the NLRP3 specific inhibitors, MCC950, and JC-124, may hold the most promise for unearthing the precise roles of the NLRP3 inflammasome in TBI, and consequently reveal potential therapies aimed to improve TBI outcomes. A table summarizing currently available therapies that have been tested in the context of TBI and shown to directly or indirectly inhibit the NLRP3 inflammasome is displayed below (Table 1).

MCC950 is a highly selective and potent NLRP3 inhibitor originally derived from the anti-diabetic drug class, sulfonylurea. MCC 950 acts by binding directly to the NACT domain of the NLRP3 protein [94]. Pre-clinical investigations on this compound have determined it to have a suitable bioavailability and pharmacokinetic profile, with good CNS penetration as well as no off-target binding of NLRC4 or the NLRP1 inflammasome [94, 95]. MCC950's specificity for the NLRP3 inflammasome and high CNS penetrability decreases the likelihood of off-target effects (a common side effect of anti-inflammatory molecules). Systemic administration of MCC950 has demonstrated promising results in pre-clinical studies of ischemic stroke, cerebral hemorrhage, and Alzheimer's disease [62, 96, 97], with two recent studies also showing some promise in the context of TBI of moderate severity $[69,70]$. The first of these studies found that acute treatment with MCC $950(50 \mathrm{mg} / \mathrm{kg}$; intraperitoneal (IP) injection) prevented increases in NLRP3 constituent proteins (NLRP3, caspase-1, ASC, and IL-1 $\beta$ ) in the cortex of mice at $24 \mathrm{~h}$ following CCI. In addition, caspase- 1 and IL-1 $\beta$ levels were decreased in MCC950-treated mice at 72 $h$ post-TBI [69]. These reductions in inflammasome activity were also accompanied by evidence of functional improvement, with treated mice displaying reduced modified neurological severity score (mNSS) compared to vehicle mice at $72 \mathrm{~h}$ post-injury [69]. The second study, performed by $\mathrm{Xu}$ et al., treated mice with MCC950 via IP injection $(10 \mathrm{mg} / \mathrm{kg})$ daily for the first 3 days post-CCI, and every second day thereafter [70]. At $72 \mathrm{~h}$ post-CCI, MCC950treated mice had reduced protein expression of NLRP3, ASC, and caspase-1. Additionally, treated mice had improvements in the mNSS and motor function at three-, seven-, and 14-day post-injury, as well as cognition at 17and 18-day post-injury [70]. Taken together, these findings suggest efficacy of MCC950 in the acute stages following focal TBI in mice; however, it is unknown whether this compound exerts beneficial effects in other species and TBI models (e.g., diffuse TBI). While systemic MCC950 treatment has shown to be well-tolerated in hypertensive mice for as long as 28 days [98], pre-clinical TBI studies have yet to treat with MCC950 for longer than 7 days. Furthermore, the effects of early MCC950 intervention on chronic TBI recovery have not yet been investigated.

Another NLRP3 inflammasome inhibitor, JC-124, has recently been investigated in the context of TBI [92]. JC124 was designed though the structural optimization of the anti-diabetic compound glyburide, in order to increase the selectivity for the NLRP3 inflammasome and hence decrease the off-target binding [99]. JC-124 acts by inhibiting the formation of the NLRP3 inflammasome [99]; however, the specific mechanisms through which this occurs are unknown. JC-124 has previously been shown in rodents to reduce inflammation and infarct size following myocardial injury [100]. In the only study on JC124 and TBI to date, Kuwar et al. found that rats given a moderate CCI followed by acute treatment with JC-124 $(100 \mathrm{mg} / \mathrm{kg}, \mathrm{IP})$ had reduced expression of NLRP3 inflammasome activation markers at $48 \mathrm{~h}$ when compared to vehicle-treated rats. Interestingly, IL-18 levels were not altered by TBI with or without JC-124 treatment [92]. Other TBI studies have also found differential expression patterns of IL-1 $\beta$ and IL-18, with IL- $1 \beta$ being the "initial responder" to injury followed by a "delayed" IL-18 response $[61,101,102]$. As such, inflammasome activation may not result in simultaneous upregulation of downstream cytokines. While no behavioral outcomes were measured in this study, JC-124 treatment was found to reduce lesion volume and the number of degenerating neurons as quantified by Fluoro-Jade B staining.

Although further studies are required, taken together these pharmacological studies have further established the link between the NLRP3 inflammasome and TBI, and suggest that treatments target this pathway may have potential for improving TBI outcomes. 


\section{NLRP3 as a biomarker for TB}

There is a growing interest to discover objective biomarkers that can assist the clinical management of TBI. In particular, fluid-based biomarkers have received much attention for their potential clinical applications, including assisting in TBI diagnosis, determination of injury severity, prediction of outcomes, monitoring of recovery, identification of underlying pathophysiology, and treatment efficacy. To date, most investigations of fluid biomarkers of TBI have focused on proteins released into CSF and blood due to axonal and glial damage; however, given the prominent role of neuroinflammation in TBI, a number of neuroinflammation-associated molecules have also recently emerged as biomarker candidates. In particular, given that astrocyte and microglia reactivity can be prominent following TBI [14-17], and these cell types are the primary cells that express NLRP3 [59, 70], it is hypothesized that NLRP3-associated molecules may have utility as biomarkers of TBI pathophysiology.

While few studies have investigated serum levels of NLRP3 inflammasome-related proteins in the context of neuroinflammatory conditions, protein levels of ASC, caspase-1, IL-1 $\beta$, and IL-18 were all found to be significantly upregulated in the serum of ischemic stroke patients compared to age-matched healthy controls [103]. Furthermore, levels of caspase-1, IL-1 $\beta$, and IL-18 were able to delineate between stroke and healthy controls, albeit with a modest degree of sensitivity and specificity [103]. Serum levels of ASC, however, were found to have significant diagnostic potential, demonstrating $100 \%$ sensitivity and $96 \%$ specificity to detect the presence of cerebral ischemia. Similarly in the context of MS, protein levels of ASC, caspase-1 and IL-18 (but not IL-1 $\beta$ ) were upregulated in the serum of multiple sclerosis patients compared to healthy age-matched controls [67], with ASC found to have the greatest diagnostic sensitivity and specificity. Furthermore, circulating ASC levels were found to have moderate ability to predict the severity of multiple sclerosis. In the context of TBI, this same group found that both ASC and caspase-1 (but not IL$1 \beta$ or IL-18) were significantly upregulated in the serum of severe-TBI patients within the first $48 \mathrm{~h}$ of injury, with both proteins having excellent utility for distinguishing between control and TBI patients [104]. Interestingly, CSF levels of IL-18 and ASC were also assessed, with both proteins found to be at upregulated and accurate indicators of TBI. However, as participants enrolled in the CSF arm of the study were not the same as the serum arm, it is impossible to determine a correlation between these two biofluids. A separate study performed by Ciaramella et al. investigated the utility of serum IL18 as a biomarker of severe-TBI in the chronic stages of recovery [105]. TBI patients at $87.8 \pm 12.7$ days postinjury had elevated serum IL-18 protein levels compared to age-matched healthy controls. Importantly, the serum IL-18 levels of the TBI patients correlated to the level of cognitive impairment and disability severity as determined by Levels of Cognitive Functioning and the Disability Rating Scale respectively [105].

The aforementioned severe-TBI studies provide the first evidence indicating a potential role for NLRP3related proteins, particularly ASC and IL-18, as fluid biomarkers of TBI. However, these two proteins are not specific to the inflammasome and as such, without direct assessments of the NLRP3 protein, do not necessarily provide an insight into the role of the NLRP3 inflammasome itself in the aftermath of TBI.

\section{Future directions}

As described above, since 2013, there have been several lines of evidence indicating that the NLRP3 inflammasome is upregulated and contributes to the pathology of TBI. While these reports are promising, there remains multiple gaps in the current literature. These gaps are described below.

mTBI: To date, there have been no specific investigations into the NLRP3 inflammasome and its potential contribution to the neuropathological and neurobehavioral effects of mTBIs. In particular, the utility of NLRP3-associated proteins as objective biomarkers of mTBI remains unexplored, but important to investigate given that the diagnosis and management of this form of injury remain notoriously difficult [106, 107]. Furthermore, in the context of sports-related mTBI, collision sports athletes are at risk of experiencing multiple mTBIs across their career. Multiple mTBIs, or repeated mTBIs, have been linked to the development of chronic deficits, including neurodegenerative diseases associated with neuroinflammation, such as CTE [5]. It is not yet known whether the NLRP3 inflammasome is involved in the potential cumulative effects of repeated mTBI; however, as the inflammasome requires a two-step activation (i.e., priming and activation), previous mTBIs may prime the inflammasome, with increased basal NLRP3 expression creating vulnerability for a subsequent mTBI to induce inflammasome activation, and as a result, an exaggerated and prolonged neuroinflammatory response.

\section{Temporal changes of the NLRP3 inflammasome}

There are inconsistencies in the current literature on the temporal profile of NLRP3 activity following TBI. Greater temporal characterization is required to both understand the contribution of the inflammasome to TBI-related neuropathological and neurobehavioral changes and to identify appropriate windows for assessment of biomarkers and application of treatments. Additionally, while one study has shown behavioral improvements at 21 days post-TBI with NLRP3 inflammasome inhibition [70], 
currently no investigations have analyzed the NLRP3 inflammasome and its inhibition beyond 7 days post-TBI. As such, future studies need to extend past these acute and sub-acute time points to investigate the role of the NLRP3 inflammasome in the chronic stages of TBI.

\section{Effect of NLRP3 inflammasome on TBI pathophysiology}

Given the increasing awareness that neuroinflammation can interact with other aspects of TBI pathophysiology, it is likely that alterations or manipulation of the NLRP3 inflammasome will have multiple pathophysiological consequences. For example, recent studies have found that a relationship exists between neuroinflammation, oxidative stress, and blood-brain barrier permeability after TBI $[84,108,109]$. The involvement of the NLRP3 inflammasome in these interactions is not yet known; however, MCC950 treatment TBI was found to reduce the extent of blood-brain barrier damage and apoptosis in the acute stages after in TBI mice [70]. NLRP3 may also interact with tau pathology, a prominent feature of chronic TBI, with Ising and colleagues recently reporting strong evidence of a bi-directional relationship between NLRP3 activation and hyperphosphorylation and aggregation of tau [110].

\section{Biological sex and the NLRP3 inflammasome}

To date, all animal studies investigating the relationship between the NLRP3 inflammasome and TBI have exclusively utilized male rodents. It is becoming increasingly appreciated that males and females can have different biological and behavioral responses to TBI [111]. Of particular relevance, there is some evidence that the nature of neuroinflammatory responses after TBI may differ between sexes. For example, Villapol and colleagues recently found that the microglial response to moderateto-severe CCI differed between sexes, with male mice displaying an earlier and more intense microglial activation when compared to female mice [112]. Interestingly, a recent study found that the NLRP3 inflammasome had a sex-dependent effect on post-operative pain, with male but not female NLRP3 knockout mice demonstrating less mechanical hypersensitivity when compared to wild type mice [113]. Although preliminary, these findings suggest that NLRP3-driven pathology may be more prominent in males. On a related note, Thakkar and colleagues recently found that activation of the NLRP3 inflammasome following ischemic brain injury was significantly impaired by estradiol signaling [114]. As such, future studies are warranted to decipher whether the nature and significance of NLRP3 activation following TBI does indeed differ between sexes.

\section{Age and the NLRP3 inflammasome}

Aging populations represent a significant proportion of all TBI patients, with 2013 reports indicating that adults over the age of 75 accounted for approximately one-third of all TBI-related deaths and hospitalizations [115]. Aging has been strongly associated with an increase in basal inflammation and dysregulation of the innate immune system [116]. Despite this, aged rodents are rarely included in pre-clinical studies [117]. Although the NLRP3 inflammasome is a key driver of the innate immune response [118], to date, no studies have investigated the NLRP3 inflammasome in aged TBI subjects. Future studies directly investigating the contribution of the NLRP3 inflammasome to the pathophysiology of TBI in aging populations is required.

\section{Novel biomarkers of the NLRP3 inflammasome}

While preliminary evidence implicating inflammasomeassociated proteins as biomarkers of TBI is promising, recent technological advances and the emergence of alternative biomarker candidates have created opportunities for discovery of other NLRP3-associated biomarkers. For example, the pro-inflammatory cytokine IL- $1 \beta$ has previously been investigated as a serum biomarker of TBI. This analysis, however, has thus far failed due to the low serum detectability of IL- $1 \beta$. Recent developments of highly sensitive assays, such as the single molecule array $\left(\mathrm{SIMOA}^{\circ}\right)$, have resulted in lower detection limits and the ability to accurately quantify $\mathrm{IL}-1 \beta$ in the periphery $[119$, 120]. Similarly, the detection of NLRP3-related molecules such as ASC has been made possible due to assays available on the Ella Simple Plex System (ProteinSimple) [103, 104]. Nonetheless, investigations into the ultimate utility of these novel biomarkers are somewhat hampered by the low accessibility to these specific immunoassay platforms. However, these assays may enable future investigations of peripheral NLRP3 inflammasome proteins in the context of neuroinflammatory-related conditions. Furthermore, short non-coding strands of RNA termed microRNAs (miRNA) are receiving growing evidence as potential biomarkers of various CNS disorders including Alzheimer's disease, Parkinson's disease, and TBI [121, 122]. miRNAs such as miR-223-3p are known regulators of the NLRP3 inflammasome and act at a priming and activation level of NLRP3 formation [123]. miRNAs, which regulate the NLRP3 inflammasome have never previously been investigated in the context TBI. Additionally, the NLRP3 inflammasome and its related proteins are not CNS specific, as the NLRP3 protein has been shown to be elevated in systemic inflammatory disorders including type 2 diabetes, atherosclerosis, and steatohepatitis [56-58]. As such, the 
implementation of novel techniques including the isolation of molecules contained in CNS-derived extracellular vesicles holds the potential to determine the cellular origin of the detected molecules and hence ensure their relevance to CNS pathology [124].

\section{Conclusions}

TBI is a global health concern; however, there are no proven therapeutic interventions to improve clinical outcomes. Recent findings from human and rodent studies have indicated an upregulation in NLRP3-related molecules following TBI. Moreover, rodent intervention studies have found that specifically inhibiting the NLRP3 inflammasome can mitigate neuroinflammation and improve outcomes following TBI. Additionally, emerging reports suggest that circulating NLRP3 and its associated molecules may function as biomarkers of neuroinflammatory conditions. Although promising, there remains a number of important knowledge gaps, including potential effects of NLRP3 inhibitors such as MCC950 on peripheral immune function and any implications this may have on host-defense mechanisms, as well as the optimal timing and dose of administration after TBI. It is recommended that further research also investigates mTBI, includes variables such as age and biological sex, determines the diagnostic and prognostic ability of inflammasome-associated biomarkers, and further establish if NLRP3-targeted treatments can improve TBI outcomes.

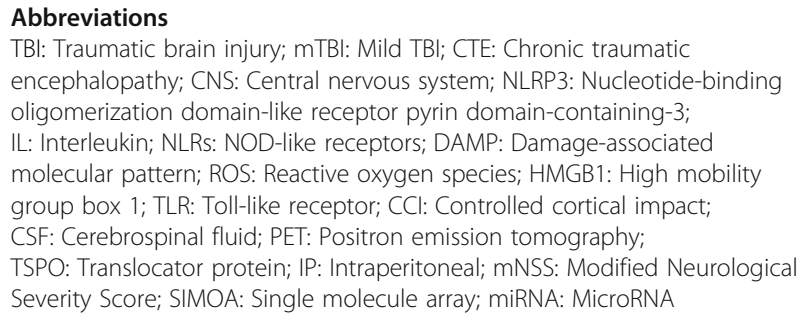

\section{Acknowledgements}

Not applicable

\section{Authors' contributions}

WTO, SJM, SRS, and MM conceived the idea of this review. WTO performed literature searching and drafted the manuscript. WTO, LP, and GFS created the figures. All authors critically reviewed and edited the content of this manuscript. All authors read and approved the final manuscript.

\section{Authors' information}

Not applicable

\section{Funding}

SRS is supported by a NHMRC fellowship

\section{Availability of data and materials}

Not applicable

Ethics approval and consent to participate

Not applicable
Consent for publication

Not applicable

\section{Competing interests}

The authors declare that they have no competing interests.

\section{Author details}

'Department of Neuroscience, Monash University, Melbourne, VIC, Australia. 2Department of Physiology, Anatomy and Microbiology, La Trobe University, Bundoora, VIC 3086, Australia. ${ }^{3}$ Department of Neurology, Alfred Health, Melbourne, VIC 3004, Australia. ${ }^{4}$ Department of Neurology, Melbourne Health, Melbourne, VIC 3004, Australia. ${ }^{5}$ Department of Physiology, The University of Melbourne, Melbourne, VIC 3052, Australia. ${ }^{6}$ Department of Medicine, University of Melbourne, Melbourne, VIC 3052, Australia.

Received: 23 January 2020 Accepted: 17 March 2020

Published online: 06 April 2020

\section{References}

1. Menon DK, Schwab K, Wright DW, Maas Al. Position statement: definition of traumatic brain injury. Arch Phys Med Rehabil. 2010;91:1637-40.

2. Maas Al. Traumatic brain injury in India: a big problem in need of data. Neurol India. 2017;65:257-8.

3. Savitsky B, Givon A, Rozenfeld M, Radomislensky I, Peleg K. Traumatic brain injury: it is all about definition. Brain Injury. 2016;30:1194-200.

4. Teasdale G, Jennett B. Assessment of coma and impaired consciousness. A practical scale. Lancet. 1974;2:81-4.

5. Mckee AC, Cantu RC, Nowinski CJ, Hedley-Whyte ET, Gavett BE, Budson AE, Santini VE, Lee HS, Kubilus CA, Stern RA. Chronic traumatic encephalopathy in athletes: progressive tauopathy after repetitive head injury. J Neuropathol Exp Neurol. 2009;68:709-35.

6. Jellinger KA. Traumatic brain injury as a risk factor for Alzheimer's disease. J Neurol Neurosurg Psychiatry. 2004;75:511-2.

7. Stern MB. Head trauma as a risk factor for Parkinson's disease. Mov Disord. 1991;6:95-7.

8. Finkbeiner NW, Max JE, Longman S, Debert C. Knowing what we don't know: long-Term psychiatric outcomes following adult concussion in sports. Can J Psychiatry. 2016;61:270-6.

9. LoBue C, Denney D, Hynan LS, Rossetti HC, Lacritz LH, Hart J, Womack KB, Woon FL, Cullum CM. Self-reported traumatic brain injury and mild cognitive impairment: increased risk and earlier age of diagnosis. J Alzheimers Dis. 2016;51:727-36.

10. Diaz-Arrastia R, Kochanek PM, Bergold P, Kenney K, Marx CE, Grimes CJB, Loh LY, Adam LGE, Oskvig D, Curley KC. Pharmacotherapy of traumatic brain injury: state of the science and the road forward: report of the Department of Defense Neurotrauma Pharmacology Workgroup. J Neurotrauma. 2014;31:135-58.

11. Ng SY, Lee AYW. Traumatic brain injuries: pathophysiology and potential therapeutic targets. Front Cell Neurosci. 2019;13:528.

12. Hukkelhoven CW, Rampen AJ, Maas Al, Farace E, Habbema JD, Marmarou A, Marshall LF, Murray GD, Steyerberg EW. Some prognostic models for traumatic brain injury were not valid. J Clin Epidemiol. 2006;59:132-43.

13. Maas Al, Stocchetti N, Bullock R. Moderate and severe traumatic brain injury in adults. Lancet Neurol. 2008;7:728-41.

14. Simon DW, McGeachy MJ, Bayir H, Clark RS, Loane DJ, Kochanek PM. The far-reaching scope of neuroinflammation after traumatic brain injury. Nat Rev Neurol. 2017:13:171-91.

15. Donat CK, Scott G, Gentleman SM, Sastre M. Microglial activation in traumatic brain injury. Front Aging Neurosci. 2017:9:208.

16. Loane DJ, Kumar A. Microglia in the TBI brain: the good, the bad, and the dysregulated. Exp Neurol. 2016;275(Pt 3):316-27.

17. Burda JE, Bernstein AM, Sofroniew MV. Astrocyte roles in traumatic brain injury. Exp Neurol. 2016;275(Pt 3):305-15.

18. Perry VH, Nicoll JA, Holmes C. Microglia in neurodegenerative disease. Nat Rev Neurol. 2010;6:193-201.

19. Gehrmann J, Matsumoto Y, Kreutzberg GW. Microglia: intrinsic immuneffector cell of the brain. Brain Res Brain Res Rev. 1995;20:269-87.

20. Yan SD, Chen X, Fu J, Chen M, Zhu H, Roher A, Slattery T, Zhao L, Nagashima M, Morser J, et al. RAGE and amyloid-beta peptide neurotoxicity in Alzheimer's disease. Nature. 1996:382:685-91.

21. Streit WJ, Kincaid-Colton CA. The brain's immune system. Sci Am. 1995;273:54-5 58-61. 
22. Brown GC, Vilalta A, Fricker M. Phagoptosis - cell death by phagocytosis plays central roles in physiology, Host Defense and Pathology. Curr Mol Med. 2015;15:842-51.

23. Rathbone AT, Tharmaradinam S, Jiang S, Rathbone MP, Kumbhare DA. A review of the neuro- and systemic inflammatory responses in post concussion symptoms: introduction of the "post-inflammatory brain syndrome" PIBS. Brain Behav Immun. 2015;46:1-16.

24. Collins-Praino LE, Corrigan F. Does neuroinflammation drive the relationship between tau hyperphosphorylation and dementia development following traumatic brain injury? Brain Behav Immun. 2017;60:369-82.

25. Cherry JD, Tripodis Y, Alvarez VE, Huber B, Kiernan PT, Daneshvar DH, Mez J, Montenigro PH, Solomon TM, Alosco ML, et al. Microglial neuroinflammation contributes to tau accumulation in chronic traumatic encephalopathy. Acta Neuropathol Commun. 2016;4:112.

26. Amor S, Peferoen LA, Vogel DY, Breur M, van der Valk P, Baker D, van Noort JM. Inflammation in neurodegenerative diseases--an update. Immunology. 2014:142:151-66

27. Ting JP, Lovering RC, Alnemri ES, Bertin J, Boss JM, Davis BK, Flavell RA, Girardin SE, Godzik A, Harton JA, et al. The NLR gene family: a standard nomenclature. Immunity. 2008;28:285-7.

28. Martinon F, Burns K, Tschopp J. The inflammasome: a molecular platform triggering activation of inflammatory caspases and processing of prolL-beta. Mol Cell. 2002;10:417-26.

29. Sutterwala FS, Ogura Y, Szczepanik M, Lara-Tejero M, Lichtenberger GS, Grant EP, Bertin J, Coyle AJ, Galan JE, Askenase PW, Flavell RA. Critical role for NALP3/CIAS1/Cryopyrin in innate and adaptive immunity through its regulation of caspase-1. Immunity. 2006;24:317-27.

30. Bauernfeind FG, Horvath G, Stutz A, Alnemri ES, MacDonald K, Speert D, Fernandes-Alnemri T, Wu J, Monks BG, Fitzgerald KA, et al. Cutting edge: NF-kappaB activating pattern recognition and cytokine receptors license NLRP3 inflammasome activation by regulating NLRP3 expression. J Immunol. 2009:183:787-91.

31. Swanson KV, Deng M, Ting JP. The NLRP3 inflammasome: molecular activation and regulation to therapeutics. Nat Rev Immunol. 2019;19:477-89.

32. Jha S, Srivastava SY, Brickey WJ, locca H, Toews A, Morrison JP, Chen VS, Gris D, Matsushima GK, Ting JP. The inflammasome sensor, NLRP3, regulates CNS inflammation and demyelination via caspase-1 and interleukin-18. J Neurosci. 2010;30:15811-20.

33. Dinarello CA. Interleukin 1 and interleukin 18 as mediators of inflammation and the aging process. Am J Clin Nutr. 2006;83:447S-55S.

34. Menu P, Vince JE. The NLRP3 inflammasome in health and disease: the good, the bad and the ugly. Clin Exp Immunol. 2011;166:1-15.

35. Bergsbaken T, Fink SL, Cookson BT. Pyroptosis: host cell death and inflammation. Nat Rev Microbiol. 2009;7:99-109.

36. Mohamed IN, Ishrat T, Fagan SC, El-Remessy AB. Role of inflammasome activation in the pathophysiology of vascular diseases of the neurovascular unit. Antioxid Redox Signal. 2015;22:1188-206.

37. Bauernfeind F, Bartok E, Rieger A, Franchi L, Nunez G, Hornung V. Cutting edge: reactive oxygen species inhibitors block priming, but not activation, of the NLRP3 inflammasome. J Immunol. 2011;187:613-7.

38. Frank MG, Weber MD, Fonken LK, Hershman SA, Watkins LR, Maier SF. The redox state of the alarmin $\mathrm{HMGB} 1$ is a pivotal factor in neuroinflammatory and microglial priming: A role for the NLRP3 inflammasome. Brain Behav Immun. 2016;55:215-24.

39. Iyer SS, Pulskens WP, Sadler JJ, Butter LM, Teske GJ, Ulland TK, Eisenbarth SC, Florquin S, Flavell RA, Leemans JC, Sutterwala FS. Necrotic cells trigger a sterile inflammatory response through the Nlrp3 inflammasome. Proc Natl Acad Sci U S A. 2009;106:20388-93.

40. Wang Y, Sedlacek AL, Pawaria S, Xu H, Scott MJ, Binder RJ. Cutting edge: the heat shock protein gp96 activates inflammasome-signaling platforms in APCs. J Immunol. 2018;201:2209-14.

41. Munoz-Planillo R, Kuffa P, Martinez-Colon G, Smith BL, Rajendiran TM, Nunez G. $K(+)$ efflux is the common trigger of NLRP3 inflammasome activation by bacterial toxins and particulate matter. Immunity. 2013;38:1142-53.

42. Murakami T, Ockinger J, Yu J, Byles V, McColl A, Hofer AM, Horng T. Critical role for calcium mobilization in activation of the NLRP3 inflammasome. Proc Natl Acad Sci U S A. 2012;109:11282-7.

43. Katsnelson MA, Rucker LG, Russo HM, Dubyak GR. K+ efflux agonists induce NLRP3 inflammasome activation independently of Ca2+ signaling. J Immunol. 2015:194:3937-52.
44. Green JP, Yu S, Martin-Sanchez F, Pelegrin P, Lopez-Castejon G, Lawrence CB, Brough D. Chloride regulates dynamic NLRP3-dependent ASC oligomerization and inflammasome priming. Proc Natl Acad Sci U S A. 2018; 115:E9371-80.

45. Gombault A, Baron L, Couillin I. ATP release and purinergic signaling in NLRP3 inflammasome activation. Front Immunol. 2012;3:414.

46. Halle A, Hornung V, Petzold GC, Stewart CR, Monks BG, Reinheckel T, Fitzgerald KA, Latz E, Moore KJ, Golenbock DT. The NALP3 inflammasome is involved in the innate immune response to amyloid-beta. Nat Immunol. 2008;9:857-65.

47. Zhong Z, Liang S, Sanchez-Lopez E, He F, Shalapour S, Lin XJ, Wong J, Ding S, Seki E, Schnabl B, et al. New mitochondrial DNA synthesis enables NLRP3 inflammasome activation. Nature. 2018:560:198-203.

48. Sorbara MT, Girardin SE. Mitochondrial ROS fuel the inflammasome. Cell Res. 2011;21:558-60.

49. Patel MN, Carroll RG, Galvan-Pena S, Mills EL, Olden R, Triantafilou M, Wolf Al, Bryant CE, Triantafilou K, Masters SL. Inflammasome priming in sterile inflammatory disease. Trends Mol Med. 2017;23:165-80.

50. Zhou R, Yazdi AS, Menu P, Tschopp J. A role for mitochondria in NLRP3 inflammasome activation. Nature. 2011;469:221-5.

51. Herman FJ, Pasinetti GM. Principles of inflammasome priming and inhibition: implications for psychiatric disorders. Brain Behav Immun. 2018; 73:66-84.

52. Werner $\mathrm{C}$, Engelhard K. Pathophysiology of traumatic brain injury. Br J Anaesth. 2007:99:4-9.

53. Prins M, Greco T, Alexander D, Giza CC. The pathophysiology of traumatic brain injury at a glance. Dis Model Mech. 2013;6:1307-15.

54. Zhang L, Wang $\mathrm{H}$. Autophagy in traumatic brain injury: a new target for therapeutic intervention. Front Mol Neurosci. 2018;11:190.

55. Hoffman HM, Mueller $\mathrm{J}$, Broide DH, Wanderer AA, Kolodner RD. Mutation of a new gene encoding a putative pyrin-like protein causes familial cold autoinflammatory syndrome and Muckle-Wells syndrome. Nat Genet. 2001; 29:301-5.

56. Zhai $Y$, Meng X, Ye T, Xie W, Sun G, Sun X. Inhibiting the NLRP3 inflammasome activation with MCC950 ameliorates diabetic encephalopathy in db/db mice. Molecules. 2018;23:522.

57. van der Heijden T, Kritikou E, Venema W, van Duijn J, van Santbrink PJ, Slutter B, Foks AC, Bot I, Kuiper J. NLRP3 inflammasome inhibition by MCC950 reduces atherosclerotic lesion development in apolipoprotein Edeficient mice-brief report. Arterioscler Thromb Vasc Biol. 2017;37:1457-61.

58. Mridha AR, Wree A, Robertson AAB, Yeh MM, Johnson CD, Van Rooyen DM, Haczeyni F, Teoh NC, Savard C, loannou GN, et al. NLRP3 inflammasome blockade reduces liver inflammation and fibrosis in experimental NASH in mice. J Hepatol. 2017:66:1037-46.

59. Liu X, Zhao Z, Ji R, Zhu J, Sui QQ, Knight GE, Burnstock G, He C, Yuan H, Xiang Z. Inhibition of P2X7 receptors improves outcomes after traumatic brain injury in rats. Purinergic Signal. 2017;13:529-44.

60. Xu KY, Wu CY, Tong S, Xiong P, Wang SH. The selective Nlrp3 inflammasome inhibitor Mcc950 attenuates lung ischemia-reperfusion injury. Biochem Biophys Res Commun. 2018;503:3031-7.

61. Liu HD, Li W, Chen ZR, Hu YC, Zhang DD, Shen W, Zhou ML, Zhu L, Hang $\mathrm{CH}$. Expression of the NLRP3 inflammasome in cerebral cortex after traumatic brain injury in a rat model. Neurochem Res. 2013:38:2072-83.

62. Dempsey C, Rubio Araiz A, Bryson KJ, Finucane O, Larkin C, Mills EL, Robertson AAB, Cooper MA, O'Neill LAJ, Lynch MA. Inhibiting the NLRP3 inflammasome with MCC950 promotes non-phlogistic clearance of amyloid-beta and cognitive function in APP/PS1 mice. Brain Behav Immun. 2017;61:306-16.

63. Yang F, Wang Z, Wei X, Han H, Meng X, Zhang Y, Shi W, Li F, Xin T, Pang Q, Yi F. NLRP3 deficiency ameliorates neurovascular damage in experimental ischemic stroke. J Cereb Blood Flow Metab. 2014;34:660-7.

64. Hoegen T, Tremel N, Klein M, Angele B, Wagner H, Kirschning C, Pfister HW, Fontana A, Hammerschmidt S, Koedel U. The NLRP3 inflammasome contributes to brain injury in pneumococcal meningitis and is activated through ATP-dependent lysosomal cathepsin B release. J Immunol. 2011; 187:5440-51.

65. Guo H, Callaway JB, Ting JP. Inflammasomes: mechanism of action, role in disease, and therapeutics. Nat Med. 2015;21:677-87.

66. Yan Y, Jiang W, Liu L, Wang X, Ding C, Tian Z, Zhou R. Dopamine controls systemic inflammation through inhibition of NLRP3 inflammasome. Cell. 2015;160:62-73. 
67. Keane RW, Dietrich WD, de Rivero Vaccari JP. Inflammasome proteins as biomarkers of multiple sclerosis. Front Neurol. 2018;9:135.

68. Deora V, Lee JD, Albornoz EA, MCAlary L, Jagaraj CJ, Robertson AAB, Atkin JD, Cooper MA, Schroder K, Yerbury JJ, et al. The microglial NLRP3 inflammasome is activated by amyotrophic lateral sclerosis proteins. Glia. 2020:68:407-21

69. Ismael S, Nasoohi S, Ishrat T. MCC950, the selective inhibitor of nucleotide oligomerization domain-like receptor protein-3 inflammasome, protects mice against traumatic brain injury. J Neurotrauma. 2018;35:1294-303.

70. Xu X, Yin D, Ren H, Gao W, Li F, Sun D, Wu Y, Zhou S, Lyu L, Yang M, et al. Selective NLRP3 inflammasome inhibitor reduces neuroinflammation and improves long-term neurological outcomes in a murine model of traumatic brain injury. Neurobiol Dis. 2018;117:15-27.

71. Lin C, Chao H, Li Z, Xu X, Liu Y, Bao Z, Hou L, Liu Y, Wang X, You Y, et al. Omega-3 fatty acids regulate NLRP3 inflammasome activation and prevent behavior deficits after traumatic brain injury. Exp Neurol. 2017;290:115-22.

72. Wallisch JS, Simon DW, Bayir H, Bell MJ, Kochanek PM, Clark RSB. Cerebrospinal fluid NLRP3 is increased after severe traumatic brain injury in infants and children. Neurocrit Care. 2017;27:44-50.

73. Pham L, Shultz SR, Kim HA, Brady RD, Wortman RC, Genders SG, Hale MW, O'Shea RD, Djouma $E$, van den Buuse $M$, et al. Mild closed-head injury in conscious rats causes transient neurobehavioral and glial disturbances: a novel experimental model of concussion. J Neurotrauma. 2019;36:2260-71.

74. Bolton AN, Saatman KE. Regional neurodegeneration and gliosis are amplified by mild traumatic brain injury repeated at 24-hour intervals. J Neuropathol Exp Neurol. 2014;73:933-47.

75. McColl TJ, Brady RD, Shultz SR, Lovick L, Webster KM, Sun M, McDonald SJ, O'Brien TJ, Semple BD. Mild traumatic brain injury in adolescent mice alters skull bone properties to influence a subsequent brain impact at adulthood: a pilot study. Front Neurol. 2018;9:372

76. Shultz SR, Bao F, Omana V, Chiu C, Brown A, Cain DP. Repeated mild lateral fluid percussion brain injury in the rat causes cumulative long-term behavioral impairments, neuroinflammation, and cortical loss in an animal model of repeated concussion. J Neurotrauma. 2012;29:281-94.

77. Ebert SE, Jensen P, Ozenne B, Armand S, Svarer C, Stenbaek DS, Moeller K, Dyssegaard A, Thomsen G, Steinmetz J, et al. Molecular imaging of neuroinflammation in patients after mild traumatic brain injury: a longitudinal (123) I-CLINDE single photon emission computed tomography study. Eur J Neurol. 2019;26:1426-32.

78. Coughlin JM, Wang Y, Munro CA, Ma S, Yue C, Chen S, Airan R, Kim PK, Adams AV, Garcia C, et al. Neuroinflammation and brain atrophy in former NFL players: an in vivo multimodal imaging pilot study. Neurobiol Dis. 2015;74:58-65.

79. Lopez-Castejon G, Brough D. Understanding the mechanism of IL-1beta secretion. Cytokine Growth Factor Rev. 2011;22:189-95.

80. Perez-Polo JR, Rea HC, Johnson KM, Parsley MA, Unabia GC, Xu G, Infante SK, Dewitt DS, Hulsebosch CE. Inflammatory consequences in a rodent model of mild traumatic brain injury. J Neurotrauma. 2013;30:727-40.

81. Weil ZM, Gaier KR, Karelina K. Injury timing alters metabolic, inflammatory and functional outcomes following repeated mild traumatic brain injury. Neurobiol Dis. 2014;70:108-16.

82. Namjoshi DR, Cheng WH, McInnes KA, Martens KM, Carr M, Wilkinson A, Fan J, Robert J, Hayat A, Cripton PA, Wellington CL. Merging pathology with biomechanics using CHIMERA (Closed-Head Impact Model of Engineered Rotational Acceleration): a novel, surgery-free model of traumatic brain injury. Mol Neurodegener. 2014;9:55.

83. Fan K, Ma J, Xiao W, Chen J, Wu J, Ren J, Hou J, Hu Y, Gu J, Yu B. Mangiferin attenuates blast-induced traumatic brain injury via inhibiting NLRP3 inflammasome. Chem Biol Interact. 2017;271:15-23.

84. Ma MW, Wang J, Dhandapani KM, Brann DW. NADPH oxidase 2 regulates NLRP3 inflammasome activation in the brain after traumatic brain injury. Oxid Med Cell Longev. 2017;2017:6057609.

85. Ma J, Xiao W, Wang J, Wu J, Ren J, Hou J, Gu J, Fan K, Yu B. Propofol inhibits NLRP3 inflammasome and attenuates blast-induced traumatic brain injury in rats. Inflammation. 2016;39:2094-103.

86. Wei $X$, Hu CC, Zhang YL, Yao SL, Mao WK. Telmisartan reduced cerebral edema by inhibiting NLRP3 inflammasome in mice with cold brain injury. J Huazhong Univ Sci Technolog Med Sci. 2016;36:576-83.

87. de Rivero Vaccari JP, Lotocki G, Alonso OF, Bramlett HM, Dietrich WD, Keane RW. Therapeutic neutralization of the NLRP1 inflammasome reduces the innate immune response and improves histopathology after traumatic brain injury. J Cereb Blood Flow Metab. 2009;29:1251-61.
88. Zheng B, Zhang S, Ying Y, Guo X, Li H, Xu L, Ruan X. Administration of Dexmedetomidine inhibited NLRP3 inflammasome and microglial cell activities in hippocampus of traumatic brain injury rats. Biosci Rep. 2018;38: BSR20180892.

89. Irrera N, Pizzino G, Calo M, Pallio G, Mannino F, Fama F, Arcoraci V, Fodale V, David A, Francesca C, et al. Lack of the Nlrp3 inflammasome improves mice recovery following traumatic brain injury. Front Pharmacol. 2017;8:459.

90. Wang ZR, Li YX, Lei HY, Yang DQ, Wang LQ, Luo MY. Regulating effect of activated NF-kappaB on edema induced by traumatic brain injury of rats. Asian Pac J Trop Med. 2016;9:274-7.

91. Jayakumar AR, Tong XY, Ruiz-Cordero R, Bregy A, Bethea JR, Bramlett HM, Norenberg MD. Activation of NF-kappaB mediates astrocyte swelling and brain edema in traumatic brain injury. J Neurotrauma. 2014;31:1249-57.

92. Kuwar R, Rolfe A, Di L, Xu H, He L, Jiang Y, Zhang S, Sun D. A novel small molecular NLRP3 inflammasome inhibitor alleviates neuroinflammatory response following traumatic brain injury. J Neuroinflammation. 2019;16:81.

93. Chen Y, Meng J, Xu Q, Long T, Bi F, Chang C, Liu W. Rapamycin improves the neuroprotection effect of inhibition of NLRP3 inflammasome activation after TBI. Brain Res. 2019;1710:163-72.

94. Coll RC, Hill JR, Day CJ, Zamoshnikova A, Boucher D, Massey NL, Chitty JL, Fraser JA, Jennings MP, Robertson AAB, Schroder K. MCC950 directly targets the NLRP3 ATP-hydrolysis motif for inflammasome inhibition. Nat Chem Biol. 2019;15:556-9.

95. Coll RC, Robertson AA, Chae JJ, Higgins SC, Munoz-Planillo R, Inserra MC, Vetter I, Dungan LS, Monks BG, Stutz A, et al. A small-molecule inhibitor of the NLRP3 inflammasome for the treatment of inflammatory diseases. Nat Med. 2015;21:248-55.

96. Ismael S, Zhao L, Nasoohi S, Ishrat T. Inhibition of the NLRP3-inflammasome as a potential approach for neuroprotection after stroke. Sci Rep. 2018;8:5971.

97. Ren H, Kong Y, Liu Z, Zang D, Yang X, Wood K, Li M, Liu Q. Selective NLRP3 (pyrin domain-containing protein 3) inflammasome inhibitor reduces brain injury after intracerebral hemorrhage. Stroke. 2018;49:184-92.

98. Krishnan SM, Ling YH, Huuskes BM, Ferens DM, Saini N, Chan CT, Diep H, Kett MM, Samuel CS, Kemp-Harper BK, et al. Pharmacological inhibition of the NLRP3 inflammasome reduces blood pressure, renal damage, and dysfunction in salt-sensitive hypertension. Cardiovasc Res. 2019;115:776-87.

99. Fulp J, He L, Toldo S, Jiang Y, Boice A, Guo C, Li X, Rolfe A, Sun D, Abbate A, et al. Structural insights of benzenesulfonamide analogues as NLRP3 inflammasome inhibitors: design, synthesis, and biological characterization. J Med Chem. 2018:61:5412-23.

100. Marchetti C, Chojnacki J, Toldo S, Mezzaroma E, Tranchida N, Rose SW, Federici M, Van Tassell BW, Zhang S, Abbate A. A novel pharmacologic inhibitor of the NLRP3 inflammasome limits myocardial injury after ischemia-reperfusion in the mouse. J Cardiovasc Pharmacol. 2014;63:316-22.

101. Woodroofe MN, Sarna GS, Wadhwa M, Hayes GM, Loughlin AJ, Tinker A, Cuzner ML. Detection of interleukin-1 and interleukin-6 in adult rat brain, following mechanical injury, by in vivo microdialysis: evidence of a role for microglia in cytokine production. J Neuroimmunol. 1991;33:227-36.

102. Yatsiv I, Morganti-Kossmann MC, Perez D, Dinarello CA, Novick D, Rubinstein M, Otto VI, Rancan M, Kossmann T, Redaelli CA, et al. Elevated intracranial IL18 in humans and mice after traumatic brain injury and evidence of neuroprotective effects of IL-18-binding protein after experimental closed head injury. J Cereb Blood Flow Metab. 2002;22:971-8.

103. Kerr N, Garcia-Contreras M, Abbassi S, Mejias NH, Desousa BR, Ricordi C, Dietrich WD, Keane RW, de Rivero Vaccari JP. Inflammasome proteins in serum and serum-derived extracellular vesicles as biomarkers of stroke. Front Mol Neurosci. 2018;11:309.

104. Kerr N, Lee SW, Perez-Barcena J, Crespi C, Ibanez J, Bullock MR, Dietrich WD, Keane RW, de Rivero Vaccari JP. Inflammasome proteins as biomarkers of traumatic brain injury. PLoS One. 2018;13:e0210128.

105. Ciaramella A, Della Vedova C, Salani F, Viganotti M, D'Ippolito M, Caltagirone C, Formisano R, Sabatini U, Bossu P. Increased levels of serum IL-18 are associated with the long-term outcome of severe traumatic brain injury. Neuroimmunomodulation. 2014:21:8-12.

106. Fischer $H$. US Military casualty statistics: operation new dawn, operation Iraqi freedom, and operation enduring freedom. In: Library of Congress Washington Dc Congressional Research service; 2013.

107. McCrory P, Meeuwisse W, Dvorak J, Aubry M, Bailes J, Broglio S, Cantu RC, Cassidy D, Echemendia RJ, Castellani RJ. Consensus statement on concussion in sport-the 5th international conference on concussion in sport held in Berlin, October 2016. Br J Sports Med. 2017;51:838-47. 
108. Kuriakose M, Younger D, Ravula AR, Alay E, Rama Rao KV, Chandra N. Synergistic role of oxidative stress and blood-brain barrier permeability as injury mechanisms in the acute pathophysiology of blast-induced neurotrauma. Sci Rep. 2019:9:7717.

109. Abdul-Muneer PM, Chandra N, Haorah J. Interactions of oxidative stress and neurovascular inflammation in the pathogenesis of traumatic brain injury. Mol Neurobiol. 2015;51:966-79.

110. Ising C, Venegas C, Zhang S, Scheiblich H, Schmidt SV, Vieira-Saecker A, Schwartz S, Albasset S, McManus RM, Tejera D, et al. NLRP3 inflammasome activation drives tau pathology. Nature. 2019;575:669-73.

111. Gupte R, Brooks W, Vukas R, Pierce J, Harris J. Sex differences in traumatic brain injury: what we know and what we should know. J Neurotrauma. 2019;36:3063-91.

112. Villapol S, Loane DJ, Burns MP. Sexual dimorphism in the inflammatory response to traumatic brain injury. Glia. 2017;65:1423-38.

113. Cowie AM, Menzel AD, O'Hara C, Lawlor MW, Stucky CL. NOD-like receptor protein 3 inflammasome drives postoperative mechanical pain in a sexdependent manner. Pain. 2019;160:1794-816.

114. Thakkar R, Wang R, Sareddy G, Wang J, Thiruvaiyaru D, Vadlamudi R, Zhang Q, Brann D. NLRP3 inflammasome activation in the brain after global cerebral ischemia and regulation by 17beta-estradiol. Oxid Med Cell Longev. 2016;2016:8309031.

115. Taylor CA, Bell JM, Breiding MJ, Xu L. Traumatic brain injury-related emergency department visits, hospitalizations, and deaths - United States, 2007 and 2013. MMWR Surveill Summ. 2017;66:1-16.

116. Shaw AC, Goldstein DR, Montgomery RR. Age-dependent dysregulation of innate immunity. Nat Rev Immunol. 2013;13:875-87.

117. Sun M, McDonald SJ, Brady RD, Collins-Praino L, Yamakawa GR, Monif M, O'Brien TJ, Cloud GC, Sobey CG, Mychasiuk R, et al. The need to incorporate aged animals into the preclinical modeling of neurological conditions. Neurosci Biobehav Rev. 2019;109:114-28.

118. Latz E, Duewell P. NLRP3 inflammasome activation in inflammaging. Semin Immunol. 2018:40:61-73.

119. Wu D, Milutinovic MD, Walt DR. Single molecule array (Simoa) assay with optimal antibody pairs for cytokine detection in human serum samples. Analyst. 2015;140:6277-82.

120. Startin CM, Ashton NJ, Hamburg S, Hithersay R, Wiseman FK, Mok KY, Hardy J, Lleo A, Lovestone S, Parnetti L, et al. Plasma biomarkers for amyloid, tau, and cytokines in Down syndrome and sporadic Alzheimer's disease. Alzheimers Res Ther. 2019;11:26.

121. Sayed D, Abdellatif M. MicroRNAs in development and disease. Physiol Rev. 2011;91:827-87.

122. Atif $H$, Hicks SD. A review of microRNA biomarkers in traumatic brain injury. J Exp Neurosci. 2019;13:1179069519832286.

123. Boxberger $N$, Hecker M, Zettl UK. Dysregulation of inflammasome priming and activation by microRNAs in human immune-mediated diseases. J Immunol. 2019;202:2177-87.

124. Tkach M, Thery C. Communication by extracellular vesicles: where we are and where we need to go. Cell. 2016;164:1226-32.

\section{Publisher's Note}

Springer Nature remains neutral with regard to jurisdictional claims in published maps and institutional affiliations.

Ready to submit your research? Choose BMC and benefit from:

- fast, convenient online submission

- thorough peer review by experienced researchers in your field

- rapid publication on acceptance

- support for research data, including large and complex data types

- gold Open Access which fosters wider collaboration and increased citations

- maximum visibility for your research: over $100 \mathrm{M}$ website views per year

At BMC, research is always in progress.

Learn more biomedcentral.com/submissions 